\section{Concursos públicos para docentes de universidades federais na perspectiva da Lei 12.990/2014: desafios à reserva de vagas para candidatas/os negras/os}

Recebido: 04.09.18 Aprovado: 25.10 .18
Luiz Mello*

\& Ubiratan Pereira de Resende**

Resumo: A partir da análise de mais de três mil editais de concursos para docentes de 63 universidades federais, tínhamos como objetivo principal problematizar os termos da implementação da

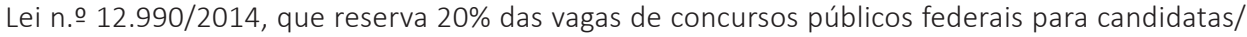
os negras/os. Uma conclusão central de nossa pesquisa é que não há uniformidade, entre as diversas universidades, quanto à interpretação do significado da exigência de um número superior a duas vagas por edital para que a reserva seja assegurada. Nesse cenário, o percentual destinado a negras/os nos editais analisados, em um período corresponde a três anos e meio, totalizando mais de 15 mil vagas, é inferior a 5\%. Tal realidade parece estar na contramão dos objetivos da Lei n. ․ 12.990/2014 e contraria manifestações de órgãos do governo federal e do Poder Judiciário no sentido de que o percentual de $20 \%$ para negras/os seja cumprido, inclusive nos concursos para docentes.

Palavras-chave: Cotas para negras/os. Concurso público. Carreira docente. Universidades federais. Lei n. 0 12.990/2014.

\section{Civil service entrance examinations for federal university faculty in the perspective of law n. - 12.990/2014: challenges in vacancy reservation for black applicants}

Abstract: With the analysis of over 3,000 notices of faculty civil service entrance examinations from 63 federal universities, our main objective was to problematize the implementation terms of Law n. 12.990 / 2014, which reserves 20\% of federal civil service examination vacancies for black applicants. A central conclusion of our research is that there is no uniformity among universities as to how to interpret the requirement of more than two vacancies per notice in order to ensure the reservation. In this scenario, the percentage allocated to black people in the analyzed notices over a period of three and a half years, totaling over 15,000 vacancies, is less than 5\%. This reality seems to be contrary to the objectives of Law n. $-12,990$ / 2014 and contradicts Federal Government and Judiciary organs' manifestations that the percentage of $20 \%$ for black people be followed, including in faculty civil service entrance examinations.

Keywords: Quotas for black people. Civil service examination. Faculty career. Federal universities. Law n.‥ 12,990/2014.

\author{
* Luiz Mello é \\ professor titular \\ de sociologia, \\ da Faculdade de \\ Ciências Sociais, da \\ Universidade Federal \\ de Goiás, Goiânia, \\ Goiás, Brasil; doutor \\ em sociologia pela \\ Universidade de \\ Brasília (UnB). \\ Orcid: 0000-0003- \\ 4387-8158. \\ <luizman@gmail. \\ com>. \\ ** Ubiratan Pereira \\ de Resende é \\ professor do \\ magistério do ensino \\ básico, técnico e \\ tecnológico do \\ Instituto Federal \\ de Brasília, Brasília, \\ Distrito Federal, \\ Brasil; doutor em \\ geografia pela \\ Universidade Federal \\ de Goiás (UFG). \\ Orcid: 0000-0003- \\ 3353-5485. \\ <up_resende@ \\ hotmail.com>.
}


Nós, pesquisadoras/es, somos formadas/ os para observar as desigualdades, as injustiças, o racismo e o sexismo fora do ambiente acadêmico e ainda nos comportamos como se o âmbito universitário fosse uma ilha de democracia e igualdade, cercado de desigualdades de todos os lados.

Ângela Figueiredo.

\section{Primeiras aproximações}

1. Somos

especialmente gratos ao professor José Jorge de Carvalho, do Departamento de Antropologia da Universidade de Brasília (UnB), a Sales Augusto dos Santos, coordenador do Setor de Pesquisa Institucional, da Universidade Federal de Viçosa (UFV), a Luana Maria Silva Vieira, assessora da Secretaria de Promoção de Políticas de Igualdade Racial (Seppir), a Antônio Teixeira Lima Júnior e a Tatiana Dias Silva, técnicos de planejamento e pesquisa do Instituto de Pesquisa Econômica Aplicada (Ipea), a Kwame Augusto Brito Akuamoa e a Eduardo Gomor dos Santos, analistas de planejamento e orçamento do Ministério do Planejamento, Desenvolvimento e Gestão (MPOG), pelo inestimável apoio no mapeamento de informações e contatos relacionados ao objeto desta investigação. $\square$ ste trabalho traz resultados de investigação relativa à aplicação da Lei n.o 12.990/2014, no âmbito dos concursos públicos para a carreira de magistério superior das 63 universidades federais ${ }^{1}$. Seu objetivo primeiro é mostrar como o percentual de $20 \%$ de reserva de vagas para negras/os, previsto na lei, não vem sendo aplicado na grande maioria dos concursos para a carreira docente, haja vista a especificidade de seus editais, os quais, muitas vezes, oferecem poucas vagas (número inferior ao mínimo de três vagas exigido pela lei para a aplicação da reserva) ou fazem uma interpretação divorciada do objetivo normativo pressuposto na lei, ao se entender que um edital, mesmo com mais de três vagas, não deve contemplar reserva para negras/os, já que estas estão distribuídas por diferentes áreas de conhecimento, geralmente com menos de três vagas por cada área. Uma das razões primeiras de nosso interesse de pesquisa fundamenta-se, portanto, na constatação de que ainda não existe consenso quanto à forma de aplicação do disposto na lei antes referida quando da realização de concursos públicos para docentes.

Nossa problematização dos impactos da Lei n. 12.990/2014 sobre a composição do corpo docente das universidades federais parte da premissa de que existe um reduzido número de professoras/es negras/os em seu quadro permanente, bem como entre os estudantes de cursos de pós-graduação stricto sensu, na contramão do crescimento significativo do número de estudantes negras/os nos cursos de graduação das universidades federais, especialmente a partir da aprovação da Lei n. ㅇ 12.711/2012, que "dispõe sobre o ingresso nas universidades federais e nas instituições federais de ensino técnico de nível médio e dá outras providências" (Brasil, 2012).

Por outro lado, parece haver razões substantivas, expostas em documentos técnicos e decisões judiciais relevantes, que tornam factível a aplicação da Lei n.o 12.990/2014 quando da realização da grande maioria dos concursos para professo- 
ras/es, como já acontece em vários casos. Desenha-se, assim, um cenário em que a totalidade das universidades federais deveria aplicar as cotas de $20 \%$ para candidatas/os negras/os em seus concursos públicos para docentes, embora não haja sinalizações claras de que haverá candidatas/os negras/os para preencher todas as vagas nas diferentes áreas de conhecimento, especialmente no caso de concursos para doutoras/es, bem como, havendo candidatas/os, se estas/es seriam aprovadas/os, haja vista o racismo estrutural que constitui a sociedade brasileira em geral e o meio acadêmico em particular.

Aplicada em seu objetivo original, a Lei n.o 12.990/2014 constitui um passo imprescindível no sentido de assegurar maior diversidade de raça/cor no conjunto de professoras/es responsável pelo acolhimento e formação de um grupo de estudantes não mais quase exclusivamente brancas/o, egressas/os de escolas privadas e originárias/os de famílias com rendimentos médios/altos, como acontecia até recentemente, especialmente nos cursos de alta demanda e elevado prestígio social. Todavia, o que se observa hoje é que tais estudantes quase nunca encontram em suas universidades professoras/es negras/es que lhes sirvam de modelo e inspiração, bem como aliadas/os na luta contra o racismo cotidiano que afeta suas vidas e dificulta sua permanência nas universidades federais.

Por outro lado, imprescindível é que as universidades federais sobrevivam em suas características constitutivas - que incluem a gratuidade do ensino, a centralidade do tripé ensino-pesquisa-extensão e a valorização de um plano de carreira docente, entre outras -, nesse cenário de crise cultural, política e econômica que assola o Brasil. Só assim haverá espaço para que as universidades federais continuem a ser centros imprescindíveis de formação profissional e de produção e divulgação de conhecimentos técnico-científicos que possibilitem níveis crescentes de justiça social e de desenvolvimento sustentável.

Nesse contexto, as reflexões a seguir expostas visam à apresentação e problematização de documentos-chave relacionados ao tema da reserva de $20 \%$ das vagas em concursos públicos para candidatas/os negras/os, bem como do perfil de raça/cor no serviço público federal, incluída a carreira de docente de educação superior das universidades federais. Outra perspectiva analítica teve como ponto de partida o mapeamento dos editais de concurso público para a carreira de magistério superior, disponibilizados em páginas Web das 63 universidades federais, no período de 9 de junho de 2014 (data de promulgação da Lei n.ำ12.990/2014) a 31 de janeiro de 2018 (marco temporal limite para o levantamento de dados), com a identificação do total de vagas oferecidas, as destinadas à ampla concorrência, aquelas reservadas a negras/os e, por fim, as previstas para pessoas com deficiência. 
Sobre a reserva de $20 \%$ das vagas em concursos públicos para candidatas/os negras/os

A Lei n.o 12.990/2014 foi a primeira lei federal a prever uma ação afirmativa fundada exclusivamente em critério de raça/cor no Brasil, haja vista que a Lei n. ㅇ 12.711/2012, que "dispõe sobre o ingresso nas universidades federais e nas instituições federais de ensino técnico de nível médio e dá outras providências", conhecida como "Lei de Cotas de Ingresso nas Universidades" ou "Lei de Cotas nas Universidades" ou "Lei de Cotas Sociais", além de prever acesso a direitos a partir de pertencimento de raça/cor, associa este a outros dois critérios de ordem socioeconômica - a obrigatoriedade da/o estudante ter cursado integralmente o ensino médio em escola pública e a reserva de um percentual de vagas específico para estudantes cuja renda familiar per capita seja igual ou inferior a 1,5 salário mínimo.

Todavia, a primeira iniciativa legislativa voltada à criação de cotas raciais no Brasil - como apresenta Antônio Sérgio Alfredo Guimarães (2016) - foi o Projeto de Lei n. -1.332 , de 7 de junho de 1983, de autoria do então deputado Abdias Nascimento (PDT/RJ), que previa, entre vários aspectos pioneiros, a reserva de pelo menos $20 \%$ de vagas para homens negros e $20 \%$ (vinte por cento) de vagas para mulheres negras, em todos os órgãos da administração pública, direta e indireta, de níveis federal, estadual e municipal, incluídos os poderes executivo, judiciário e legislativo, e em todos os níveis de atividade profissional privada, especialmente naqueles de melhor qualificação e melhor remuneração (arts. 2ㅇe 3ํ). Aprovado, por unanimidade, nas comissões de Constituição e Justiça, de Trabalho e Legislação Social e de Finanças, esse projeto foi arquivado em 5 de abril de 1989, antes de ser apreciado pelo Plenário da Câmara dos Deputados.

A Universidade de Brasília (UnB) foi a primeira instituição federal de ensino superior a aprovar, por decisão administrativa própria, um programa de cotas específicas para negras/os em seus cursos de graduação, a partir de proposta apresentada pelos professores José Jorge de Carvalho, Rita Laura Segato e grupo de apoiadoras/ es (Carvalho \& Segato, 2002). Carvalho, já em meados dos anos 2000, reporta-se à urgência da criação de um programa de ações afirmativas também para estudantes negras/os e para indígenas nos cursos de pós-graduação stricto sensu e nas carreiras de professor/a de universidades públicas e de pesquisador/a, como se observa a seguir: 
cotas imediatamente para garantir a inclusão de um mínimo de professores negros, porque se deixamos o sistema como está, já sabemos que essa inclusão racial não ocorrerá. [...] que eu saiba, o tema da exclusão racial na docência superior não está colocado em discussão por nenhum dos atores principais da Reforma Universitária. Tanto o Ministério da Educação (MEC) quanto o Sindicato Nacional dos Docentes das Instituições de Ensino Superior (Andes), a Associação Nacional dos Dirigentes das Instituições Federais de Ensino Superior no Brasil (Andifes) e a União Nacional dos Estudantes (UNE) continuam silenciando o drama do nosso racismo acadêmico (Carvalho, 2005: 7, grifos nossos).

Três anos antes da aprovação da Lei n.o 12.711/2012, em meio às intensas disputas acadêmicas e políticas acerca da legitimidade das cotas raciais, o Sistema de Cotas para Negros da UnB, então em vigor já havia cinco anos, foi objeto da Arguição de Descumprimento de Preceito Fundamental (ADPF) n.o 186, apresentada pelo Partido Democratas (DEM), junto ao Supremo Tribunal Federal (STF), em 20 de julho de 2009, com pedido de suspensão liminar não só em relação aos sistema de cotas da UnB, mas também solicitando que "os juízes e Tribunais de todo país suspendam todos os processos que envolvam a aplicação do tema cotas raciais para ingresso nas universidades" (Democratas, 2009: 77).

Em 26 de abril de 2012, o Plenário do Supremo Tribunal Federal (STF), nos termos do voto do relator, ministro Ricardo Lewandowski, julgou, por unanimidade, improcedente a ADPF que questionava a constitucionalidade do sistema de cotas para negros da UnB.

Nesse cenário, a Lei n.o 12.990, sancionada pela então presidenta Dilma Roussef em 9 de junho de 2014, reserva a candidatas/os negras/os 20\% das vagas oferecidas nos concursos públicos da administração pública federal, nos três níveis de poder (Executivo, Legislativo e Judiciário), incluídas as autarquias, fundações públicas, empresas públicas e sociedades de economia mista controladas pela União, pelo prazo de dez anos. O projeto que deu origem a esta lei foi encaminhado pelo Poder Executivo ao Congresso Nacional, em regime de urgência, em 4 de novembro de 2013, com o objetivo de regulamentar o disposto no art. 39, § 2으, da Lei n. 9 12.888/2010 (Estatuto da Igualdade Racial), o qual estabelece que o poder público promoverá ações que assegurem a igualdade de oportunidades no mercado de trabalho para a população negra, incluídas as contratações no setor público.

Nos termos da Lei n. 12.990/2014, a reserva de 20\% para negras/os será aplicada sempre que o número de vagas oferecidas no concurso público for igual ou superior a três, devendo constar expressamente nos editais o número de vagas correspon- 
dente à reserva para cada cargo ou emprego público, com arredondamento para o número inteiro subsequente sempre que ocorrer fracionamento igual ou maior que 0,5 (cinco décimos). Poderão concorrer às vagas reservadas para negras/os as/ os candidatas/os que se autodeclararem pretas/os ou pardas/os no ato da inscrição no concurso, na forma como o Instituto Brasileiro de Geografia e Estatística (IBGE) utiliza o quesito cor ou raça nos censos demográficos, facultados procedimentos administrativos voltados ao combate à fraude na autodeclaração, tanto durante a realização do concurso quanto após eventual nomeação de candidatas/os, assegurados o contraditório e a ampla defesa.

Três meses antes da aprovação da Lei n.o 12.990/2014, o Instituto de Pesquisa Econômica Aplicada (Ipea) divulgou a nota técnica n.ำ 17, sobre a "reserva de vagas para negros em concursos públicos: uma análise a partir do Projeto de Lei n. - 6.738/2013", de autoria de Tatiana Dias Silva e Josenilton Marques da Silva, os quais destacam que

a apresentação do PL oferece um avanço na concepção e atuação do governo federal para a questão racial; notadamente, ao propor cotas com critério racial único, reconhece o peso do racismo como elemento estruturante das desigualdades [...] (Silva \& Silva, 2014: 3).

Os autores chamam ainda a atenção para o fato de que

$$
\begin{aligned}
& \text { a presença da população negra é muito mais reduzida em carreiras } \\
& \text { mais valorizadas, especialmente as de nível superior, e que ofere- } \\
& \text { cem melhor remuneração (Silva \& Silva, 2014: 9). }
\end{aligned}
$$

Considerações de natureza semelhante são apresentadas em outros trabalhos que também investigam ações afirmativas com base em raça/cor nos quadros da administração pública, a exemplo dos de Tatiana Dias Silva (2014), Tatiana Dias Silva e Ana Paula Sampaio Volpe (2013), Ana Paula Sampaio Volpe e Tatiana Dias Silva (2016) e Marcilene Garcia de Souza (2010) - este último consistindo em uma exaustiva análise da pioneira lei de cotas do estado do Paraná, que institui reserva de $10 \%$ das vagas de concursos públicos para negras/os.

A nota técnica do Ipea é particularmente relevante, entre outros aspectos, por antever a potencial dificuldade de aplicação do percentual de reserva de vagas para negras/os no caso dos concursos públicos para docentes de universidades federais, ao mesmo tempo em que aponta caminhos para a superação do aparente impasse, como se observa a seguir: 
Outro ponto de destaque são os concursos com baixo número de vagas, entre os quais o exemplo mais contundente talvez seja o magistério superior. Geralmente, há menos de três vagas para cada cargo, tendo em vista a especialização requerida. Assim, no espaço universitário, embora seja o "nascedouro" das ações afirmativas para negros, a lei não surtirá muito efeito. Desse modo, convém avaliar este tipo de concurso e outros que congreguem as mesmas características e propor medidas alternativas para ampliação da representação racial em cargos específicos, conjugando, além da reserva de vagas, ações como estratégias de recrutamento voltadas para a população negra habilitada, alteração no formato dos concursos (ampliando o espectro de atuação do cargo, de modo a permitir aglutinação de vagas, quando possível), entre outras táticas inovadoras e mais oportunas que as próprias instituições poderão formular (Silva \& Silva, 2014: 17, grifos nossos).

Por outro lado, a nota técnica n. 43/2015, da Secretaria de Políticas de Promoção da Igualdade Racial (Seppir), sobre o tema "Manifestações a propósito das várias consultas à Seppir quanto a questões referentes à aplicação da Lei n. 12.990/2014", igualmente faz alusão expressa à necessidade de cumprimento do disposto na Lei n.ำ 12.990/2014 no âmbito de situações similares à dos concursos para docentes, nos seguintes termos:

[...] resta evidente que a legislação frisa que a reserva de vagas incide sobre $20 \%$ da totalidade das vagas oferecidas no concurso público, ou seja, as vagas reservadas devem ser proporcionais ao total destinado ao concurso público.

$[\ldots]$

Assim, não é possivel que os dispositivos que regulam os concursos públicos, os editais, prevejam o fracionamento do cálculo das vagas ofertadas no concurso. O percentual deve ser aplicado sobre o total das vagas ofertadas, as quais não devem ser consideradas de forma individual, pois essa fragmentação não se justifica legalmente (Seppir, 2015: 5-6, grifos nossos).

Nesse cenário, o Conselho Federal da Ordem dos Advogados do Brasil (CFOAB), em 26 de janeiro de 2016, protocolou a Ação Declaratória de Constitucionalidade (ADC) n. .41 , tendo por objeto a Lei n. 12.990/2014,

[...] a fim de reprimir toda e qualquer postura divergente, tanto em relação à constitucionalidade da reserva de vagas nos concursos para cargos efetivos e empregos públicos, quanto em relação ao respeito do procedimento da autodeclaração (Conselho Federal da Ordem dos Advogados do Brasil, 2016: 4). 
Na ADC em questão, a OAB defende a constitucionalidade da reserva de vagas para pessoas negras no serviço público federal, com destaque para o entendimento de que

[...] as cotas nos serviços públicos representam uma extensão das cotas universitárias, uma evolução das ações afirmativas no combate ao racismo e à desigualdade racial no país (Conselho Federal da Ordem dos Advogados do Brasil, 2016: 20, grifos nossos).

Em 8 de junho de 2017, o Plenário do Supremo Tribunal Federal aprovou, por unanimidade, o relatório do ministro Luís Roberto Barroso, que estabeleceu a constitucionalidade da Lei n.․ 12.990/2014, a partir de três argumentos principais:

1. consonância da ação afirmativa em questão com o princípio da isonomia, uma vez que visa a assegurar igualdade material e igualdade como reconhecimento, com vistas à superação do racismo estrutural e institucional prevalecente no Brasil;

2. inviolabilidade dos princípios do concurso público e da eficiência, considerando que a reserva de vagas para negros não os isenta da aprovação no concurso público - passam a coexistir dois critérios distintos de preenchimento de vagas, assegurado o parâmetro mínimo de suficiência em ambos os casos; e

3. observância do princípio da proporcionalidade - afinal, são reservadas apenas $20 \%$ das vagas, quando mais de $50 \%$ da população brasileira se autodeclara negra, segunda dados da Pesquisa Nacional por Amostragem de Domicílios (Pnad), realizada pelo Instituto Brasileiro de Geografia e Estatística (IBGE) - e constatação de que a existência de política de cotas para o acesso de negras/os à educação superior não torna a reserva de vagas nos quadros da administração pública desnecessária.

Cabe destacar ainda que, nesse voto, de maneira expressa e praticamente literal, estão contempladas as quatro recomendações fundamentais apresentadas na antes referida nota técnica $\mathrm{n}$. 은 17 , do Ipea, uma das quais especialmente relacionada à especificidade de concursos para docentes do ensino superior, nos seguintes termos:

Por fim, a administração pública deve atentar para os seguintes parâmetros: (i) os percentuais de reserva de vaga devem valer para todas as fases dos concursos; (ii) a reserva deve ser aplicada em todas as vagas oferecidas no concurso público (não apenas no edi- 
tal de abertura); (iii) os concursos não podem fracionar as vagas de acordo com a especialização exigida para burlar a política de ação afirmativa, que só se aplica em concursos com mais de duas vagas; e (iv) a ordem classificatória obtida a partir da aplicação dos critérios de alternância e proporcionalidade na nomeação dos candidatos aprovados deve produzir efeitos durante toda a carreira funcional do beneficiário da reserva de vagas (Brasil, STF, 2017: 3 , grifos nossos).

Mais especificamente no tocante à aplicação do percentual de $20 \%$ de reserva de vagas para candidatas/os negras/os nos concursos para professor/a de universidades federais, o ministro Luís Roberto Barroso assim se expressa em seu voto:

\begin{abstract}
Além disso, a nota técnica [do Ipea] faz referência [...]. Relata, ainda, que em concursos com baixo número de vagas, como o magistério superior (considerando a divisão do concurso por especialidade), a lei pode vir a não surtir efeito [...] [E complementa:] deve-se aglutinar, sempre que possivel, as vagas em concursos com baixo número de vagas (Brasil, STF, 2017: 37 e 39, grifos nossos).
\end{abstract}

Quase três anos antes dessa manifestação do plenário do Supremo Tribunal Federal acerca da ADC n.o 41/2017, e pouco mais de quatro meses após a aprovação da Lei n.o 12.990/2014, a Procuradoria Federal junto à Universidade Federal da Grande Dourados (UFGD), vinculada à Procuradoria-Geral Federal (PGF), da Advocacia-Geral da União (AGU), emitiu o Parecer n. 74/2014/PF-UFGD/PGF/AGU, em 22 de outubro de 2014, respondendo demanda da Coordenadoria do Centro de Seleção da UFGD acerca do edital de concurso público para provimento de cargos de docentes do magistério superior. Este parecer recomendou expressamente a aplicação da reserva de $20 \%$ das 81 vagas do concurso em questão, o que corresponderia a 16 vagas, para pessoas negras, nos termos da Lei n. 12.990/2014, e também recomendou reserva de $5 \%$ das mesmas 81 vagas, totalizando cinco vagas, para pessoas com deficiência, na forma prevista no Decreto n.․ 3.298/1999.

O parecer acima referido faz alusão expressa ao fato de que as mencionadas 81 vagas previstas no edital se distribuem por 73 áreas de conhecimento, o que implicaria a possibilidade, julgada integralmente procedente pela PGF da UFGD, de que mesmo áreas que tenham oferecido apenas uma vaga no concurso possam vir a reservá-la para candidata/o com deficiência ou negra/o, a partir de sorteio previamente realizado pela administração da UFGD, considerando que os percentuais de reserva devem ser aplicados sobre o total de vagas estabelecido no edital e não sobre os subtotais relativos às vagas de áreas de conhecimento específicas. Está claro que o entendimento adotado no parecer visa evitar a inviabilização da aplica- 
ção da Lei n. $12.990 / 2014$ no caso do concurso em questão, em completa sintonia com a antes mencionada nota técnica n. $\circ$ 17, do Ipea, a nota técnica $n . \circ 43 / 2015$, da Seppir, e o antes referido voto do relator da ADC n.․41/2017.

Em 26 de agosto de 2016, foi a vez da Procuradoria Federal junto à Universidade Federal do Oeste do Pará (Ufopa), com sede em Santarém (PA), emitir o Parecer n. o 135/2016/PF-Ufopa/PGF, a pedido da Pró-Reitoria de Planejamento Institucional da Ufopa, acerca de "minuta de edital de concurso público para provimento de cargos de professor da carreira do magistério superior para os campi do interior da Ufopa". Além de diversos outros aspectos relativos à legalidade do edital em análise, o Parecer n.o 135 em questão trata especificamente da necessidade de assegurar a reserva de $20 \%$ das vagas do concurso para candidatas/os negras/os,

[...] considerando-se o fato de estarmos tratando de legislação nova no ordenamento jurídico e, ainda, o fato de os concursos públicos para docentes das Instituições Federais de Ensino Superior (Ifes) terem certas peculiaridades como, por exemplo, a divisão das vagas em temas, embora se trate da oferta do mesmo cargo (professor de magistério superior) (Brasil, 2016: 11, grifos nossos).

A Procuradoria Federal da Ufopa ainda sugere a adoção do mesmo formato proposto no Parecer n. o 074/2014/PF-UFGD/PGF/AGU, antes mencionado, para a definição das vagas a serem reservadas para pessoas com deficiência e para pessoas negras, incluindo o caso das áreas de conhecimento que preveem apenas uma vaga no edital, qual seja, o sorteio, reproduzindo, na íntegra, a longa argumentação apresentada como justificativa para essa opção pela Procuradoria Federal da UFGD.

\section{Sobre raça/cor no serviço público federal e nos concursos para docentes das universidades federais}

Não o é tarefa simples tentar dimensionar os impactos decorrentes da aprovação da Lei n.o 12.990/2014 sobre o perfil de raça/cor das/os servidoras/es públicas/os federais, incluídas/os as/os docentes da carreira de magistério superior das universidades federais. Antes de mais nada, porque não há monitoramento sistemático e contínuo da aplicação da lei em si, mas também porque o governo federal não contempla a variável raça/cor em seu Painel Estatístico de Pessoal, disponível e atualizado mensalmente na página Web do MPOG. Da mesma forma, no documento elaborado pela Escola Nacional de Administração Pública (Enap), intitulado Servidores Públicos Federais - Perfil 2015 (Brasil, 2015), não aparece a variável raça/ cor na caracterização do perfil de servidoras/es públicas/os federais, no âmbito dos poderes executivo, judiciário e legislativo. 
As informações públicas mais recentes relativas ao perfil de raça/cor de servidoras/es públicas/os federais estão disponíveis em outro documento da Enap (Brasil, 2014), com nível de detalhamento que contempla também sexo, escolaridade, órgão de atuação, nível do cargo ocupado, entre outras características, a partir de dados extraídos do acima mencionado Sistema Integrado de Administração de Recursos Humanos (Siape), em junho de 2014, coincidentemente, mês e ano de aprovação da Lei n.o 12.990. Esse mapeamento restringe-se, porém, à esfera do Executivo, com as informações relativas à raça/cor sendo resultantes de autodeclaração facultativa. Isso implica dizer que há um percentual de servidoras/es que optaram por não declarar ou não foram questionadas/os sobre sua raça/cor quando ingressaram no serviço público federal. Também deve ser registrado que, nesse documento da Enap, a nomenclatura utilizada para raça/cor é a do Siape, que difere da do IBGE, já que este usa a expressão "preta" enquanto aquele usa a expressão "negra", reunindo pretas/os e pardas/os. De acordo com o levantamento da Enap em questão (Brasil, 2014), do total de servidoras/es públicas federais do Executivo, 51,7\% se autodeclararam brancas/os; 22,4\%, pardas; $4 \%$, negras/os (pretas/os, nos termos do IBGE); 3,4\%, amarelas/os; 0,3\%, indígenas; e 18,2\% não informaram sua raça/cor.

Especificamente no que diz respeito à autodeclaração de raça/cor das/os docentes da carreira de magistério superior das universidades federais, utilizamos como fonte para a construção da Tabela 1, abaixo, os Censos da Educação Superior (2008, 2009, 2013, 2014, 2015 e 2016), realizados pelo Inep, que reúnem dados do Siape relativos ao perfil do corpo docente das universidades federais.

TABELA 1

DOCENTES DAS 63 UNIVERSIDADES FEDERAIS, POR RAÇA/COR AUTODECLARADA (2008, 2009, 2013, 2014, 2015 E 2016)

\begin{tabular}{|c|c|c|c|c|c|c|c|c|c|}
\hline \multirow{2}{*}{ Ano } & \multirow{2}{*}{ 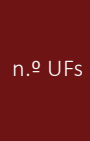 } & $\begin{array}{c}\text { n. } . \text { de } \\
\text { docentes }\end{array}$ & \multicolumn{7}{|c|}{ Raça/Cor autodeclarada } \\
\hline & & Total & Branca & Preta & Parda & Amarela & Indígena & $\begin{array}{l}\text { Não } \\
\text { dispõe }\end{array}$ & $\begin{array}{c}\text { Não } \\
\text { declarado }\end{array}$ \\
\hline 2008 & - & 51.838 & - & - & - & - & - & - & - \\
\hline 2009 & 55 & 69.778 & 19.727 & 745 & 4.057 & 403 & 58 & 24.537 & 20.251 \\
\hline 2013 & 62 & 85.507 & 24.811 & 1.000 & 5.995 & 609 & 91 & 29.857 & 23.144 \\
\hline 2014 & 63 & 88.748 & 30.283 & 1.283 & 7.948 & 870 & 131 & 7.424 & 40.809 \\
\hline 2015 & 63 & 91.337 & 31.956 & 1.144 & 8.281 & 911 & 138 & 7.755 & 41.152 \\
\hline 2016 & 63 & 94.328 & 32.121 & 1.364 & 8.900 & 928 & 143 & 00 & 50.872 \\
\hline \multicolumn{2}{|c|}{$2016(\%)$} & $100 \%$ & $34 \%$ & $1 \%$ & $9 \%$ & $1 \%$ & $0 \%$ & $0 \%$ & $54 \%$ \\
\hline
\end{tabular}


Como se pode observar na Tabela 1, entre docentes das universidades federais também prevalecem as/os que se autodeclaram brancas/os (34\%, em 2016), com percentuais muito inferiores de autodeclaradas/os pardas/os e pretas/os ( $9 \%$ e $1 \%$, respectivamente, em 2016). O que salta aos olhos de maneira bastante expressiva também é o altíssimo percentual de docentes que não declararam sua raça/cor, $54 \%$, praticamente três vezes o percentual encontrado no conjunto de servidoras/ os públicas/os federais do Executivo que também não declaram raça/cor em 2014 $(18,2 \%)$, como destacado acima. Com essa elevada lacuna de informações relativas à raça/cor, fica difícil qualquer esforço de detalhamento do perfil de raça/cor do corpo docente das universidades federais, ainda que exista uma altíssima probabilidade de que haja uma maioria absoluta de brancas/os, considerando que, entre as/ os docentes que autodeclararam sua raça/cor, 79\% são brancas/os.

Quando se observam as informações relativas à raça/cor autodeclarada das/os docentes de cada uma das 63 universidades federais, a partir da Tabela 2, construída a partir de dados do Censo da Educação Superior do Inep relativos a 2016, reafirmam-se os resultados apresentados na Tabela 1 - níveis elevados de docentes autodeclaradas/os brancas/os e/ou que não declararam raça/cor -, respeitadas as eventuais especificidades de cada instituição. Um levantamento mais detalhado do perfil dos docentes das universidades federais, a partir de dados do Censo da Educação Superior, do Inep, poderia correlacionar os percentuais de autodeclaração de raça/ cor com outros atributos identitários, a exemplo de sexo, idade, área de formação, titulação e área de atuação, entre outros.

Esse perfil de raça/cor como pano de fundo aponta na direção de expressiva ausência de pardas/os e pretas/os no conjunto de professoras/es das universidades federais, quadro igualmente preocupante se descortina a partir do mapeamento que realizamos de mais de três mil editais de concursos públicos para a carreira de magistério superior das 63 universidades federais brasileiras, divulgados no período entre 9 de junho de 2014 (data de sanção da Lei n. o 12.990/2014) e 31 de janeiro de 2018 (limite temporal que estabelecemos para o levantamento de dados), com identificação do total de vagas oferecido por região geográfica, estado e instituição, bem como a especificação das vagas de ampla concorrência, as reservadas para candidatas/os negras/os e as previstas para candidatas/os com deficiência, conforme apresentado na Tabela 3.

Deve ser ressaltado que o levantamento de vagas aqui apresentado não é exaustivo, haja vista que nem todas as universidades federais disponibilizam a totalidade de seus editais nas respectivas páginas Web, nossa principal fonte de pesquisa, o que dificultou um mapeamento completo do total de vagas reservadas para candidatas/ 
TABELA 2

RAÇA/COR AUTODECLARADA DE DOCENTES

DAS 63 UNIVERSIDADES BRASILEIRAS (2016)

\begin{tabular}{|c|c|c|c|c|c|c|c|c|}
\hline \multirow[b]{2}{*}{ Estado } & \multirow{2}{*}{$\begin{array}{c}\text { Universidades } \\
\text { Federais }\end{array}$} & \multirow{2}{*}{$\begin{array}{c}\text { Docentes } \\
\text { Total }\end{array}$} & \multicolumn{6}{|c|}{ Raça/Cor autodeclarada } \\
\hline & & & Branca & Preta & Parda & Amarela & Indígena & $\begin{array}{c}\text { Não } \\
\text { declarado }\end{array}$ \\
\hline \multicolumn{9}{|c|}{ Região Norte } \\
\hline$A C$ & UFAC & 904 & 139 & 19 & 349 & 1 & 2 & 394 \\
\hline AP & Unifap & 688 & 63 & 21 & 104 & 1 & 3 & 496 \\
\hline AM & Ufam & 1.937 & 108 & 10 & 145 & 5 & 1 & 1.668 \\
\hline \multirow{4}{*}{ PA } & Ufopa & 403 & 126 & 22 & 141 & 9 & 2 & 103 \\
\hline & Ufpa & 2.611 & 80 & 40 & 100 & 8 & 7 & 2.376 \\
\hline & Ufra & 403 & 123 & 7 & 270 & 2 & 0 & 1 \\
\hline & Ufesspa & 299 & 86 & 32 & 140 & 1 & 0 & 40 \\
\hline RO & Unir & 818 & 431 & 16 & 200 & 9 & 3 & 159 \\
\hline RR & UFRR & 595 & 208 & 15 & 142 & 10 & 9 & 211 \\
\hline TO & UFT & 1.137 & 634 & 84 & 296 & 18 & 3 & 102 \\
\hline \multicolumn{9}{|c|}{ Região Nordeste } \\
\hline$A L$ & Ufal & 1.719 & 414 & 8 & 113 & 0 & 0 & 1.184 \\
\hline \multirow{4}{*}{ BA } & Ufba & 2.954 & 1.352 & 38 & 828 & 55 & 12 & 669 \\
\hline & Ufob & 268 & 100 & 31 & 77 & 2 & 0 & 58 \\
\hline & UFRB & 880 & 326 & 104 & 284 & 12 & 2 & 152 \\
\hline & UFSB & 193 & 109 & 14 & 54 & 2 & 2 & 12 \\
\hline \multirow{3}{*}{ CE } & UFC & 1.934 & 17 & 1 & 17 & 0 & 0 & 1.899 \\
\hline & Ufca & 280 & 82 & 7 & 61 & 9 & 4 & 117 \\
\hline & Unilab & 282 & 106 & 45 & 73 & 1 & 2 & 55 \\
\hline MA & Ufma & 1.914 & 753 & 157 & 613 & 30 & 5 & 356 \\
\hline \multirow{2}{*}{ PB } & UFPB & 2.760 & 272 & 33 & 193 & 10 & 1 & 2.251 \\
\hline & UFCG & 1.699 & 374 & 16 & 195 & 0 & 0 & 1.114 \\
\hline \multirow{3}{*}{$P E$} & UFPE & 3.081 & 205 & 19 & 111 & 5 & 0 & 2741 \\
\hline & UFRPE & 1.226 & 702 & 17 & 398 & 52 & 0 & 57 \\
\hline & Univasf & 612 & 288 & 37 & 170 & 16 & 4 & 97 \\
\hline $\mathrm{PI}$ & Ufpi & 2.073 & 132 & 46 & 217 & 3 & 3 & 1.672 \\
\hline \multirow{2}{*}{ RN } & UFRN & 2.927 & 48 & 1 & 62 & 0 & 0 & 2.816 \\
\hline & Ufersa & 754 & 90 & 7 & 76 & 2 & 0 & 579 \\
\hline SE & UFS & 1.810 & 22 & 1 & 53 & 0 & 0 & 1.734 \\
\hline
\end{tabular}

os negras/os no período aproximado de três anos e meio antes especificado. A título de exemplos dessa situação, observe-se como foram registradas na Tabela 3 apenas 15 vagas de concurso para docentes na Universidade Federal de Viçosa (UFV) e 18 vagas para docentes na Universidade Federal de Itajubá (Unifei), números prova- 
... $/ \cdots$

\begin{tabular}{|c|c|c|c|c|c|c|c|c|}
\hline \multirow[b]{2}{*}{ Estado } & \multirow{2}{*}{$\begin{array}{c}\text { Universidades } \\
\text { Federais }\end{array}$} & \multirow{2}{*}{$\begin{array}{c}\text { Docentes } \\
\text { Total }\end{array}$} & \multicolumn{6}{|c|}{ Raça/Cor autodeclarada } \\
\hline & & & Branca & Preta & Parda & Amarela & Indígena & $\begin{array}{c}\text { Não } \\
\text { declarado }\end{array}$ \\
\hline \multicolumn{9}{|c|}{ Região Centro-Oeste } \\
\hline DF & UnB & 3.034 & 1.904 & 62 & 496 & 62 & 12 & 498 \\
\hline GO & UFG & 2.942 & 752 & 6 & 30 & 1 & 0 & 2.153 \\
\hline \multirow{2}{*}{ MS } & UFGD & 652 & 27 & 1 & 7 & 0 & 0 & 617 \\
\hline & UFMS & 1.741 & 1.047 & 42 & 255 & 48 & 12 & 337 \\
\hline MT & UFMT & 2.240 & 1.148 & 7 & 424 & 133 & 5 & 523 \\
\hline \multicolumn{9}{|c|}{ Região Sudeste } \\
\hline ES & Ufes & 1.896 & 1472 & 53 & 307 & 30 & 6 & 28 \\
\hline \multirow{11}{*}{ MG } & UFJF & 1.732 & 323 & 8 & 53 & 4 & 0 & 1.344 \\
\hline & UFSJ & 873 & 7 & 0 & 1 & 0 & 0 & 865 \\
\hline & Ufla & 746 & 7 & 0 & 0 & 1 & 0 & 738 \\
\hline & UFMG & 3.473 & 100 & 0 & 20 & 0 & 0 & 3.353 \\
\hline & Ufop & 1.001 & 346 & 16 & 105 & 4 & 1 & 529 \\
\hline & UFU & 1.992 & 1.454 & 33 & 195 & 39 & 2 & 269 \\
\hline & UFV & 1.244 & 293 & 14 & 49 & 2 & 0 & 886 \\
\hline & UFTM & 590 & 509 & 2 & 40 & 12 & 1 & 26 \\
\hline & UFVJM & 779 & 295 & 37 & 156 & 3 & 3 & 285 \\
\hline & Unifal & 550 & 179 & 4 & 17 & 1 & 0 & 349 \\
\hline & Unifei & 493 & 56 & 0 & 5 & 2 & 0 & 430 \\
\hline \multirow{4}{*}{ RJ } & UFF & 3.701 & 2.037 & 43 & 143 & 21 & 3 & 1.454 \\
\hline & UFRRJ & 919 & 12 & 0 & 2 & 0 & 0 & 905 \\
\hline & Unirio & 871 & 220 & 2 & 19 & 1 & 1 & 628 \\
\hline & UFRJ & 4.102 & 1.229 & 27 & 118 & 4 & 1 & 2.723 \\
\hline \multirow{3}{*}{$S P$} & UFABC & 686 & 561 & 10 & 55 & 33 & 3 & 24 \\
\hline & UFSCar & 1.459 & 1.303 & 6 & 79 & 26 & 1 & 44 \\
\hline & Unifesp & 1.574 & 1.261 & 18 & 66 & 72 & 3 & 154 \\
\hline \multicolumn{9}{|c|}{ Região Sul } \\
\hline \multirow{2}{*}{ PR } & UFPR & 2411 & 34 & 0 & 1 & 1 & 0 & 2.375 \\
\hline & UTFPR & 2.908 & 2.416 & 34 & 230 & 112 & 9 & 107 \\
\hline \multirow{8}{*}{ RS } & Furg & 974 & 789 & 21 & 66 & 9 & 5 & 84 \\
\hline & UFCSPA & 337 & 324 & 0 & 1 & 1 & 0 & 11 \\
\hline & UFFS & 796 & 701 & 14 & 42 & 9 & 2 & 28 \\
\hline & UFPel & 1.494 & 38 & 0 & 1 & 0 & 0 & 1.455 \\
\hline & UFRGS & 2.846 & 940 & 10 & 18 & 11 & 4 & 1.863 \\
\hline & UFSM & 2.128 & 2.011 & 13 & 62 & 8 & 1 & 33 \\
\hline & Unila & 381 & 8 & 7 & 296 & 11 & 0 & 59 \\
\hline & Unipampa & 996 & 857 & 25 & 53 & 4 & 3 & 54 \\
\hline SC & UFSC & 2.606 & 71 & 1 & 6 & 0 & 0 & 2.528 \\
\hline TOTAL & & 94.328 & 32.121 & 1.364 & 8.900 & 928 & 143 & 50.872 \\
\hline
\end{tabular}

Fonte: os autores (2018). 
TABELA 3

VAGAS OFERECIDAS EM CONCURSOS PÚBLICOS DA CARREIRA DE MAGISTÉRIO SUPERIOR, DAS 63 UNIVERSIDADES FEDERAIS, NO PERÍODO DE 09.06.2014 A 31.01.2018

\begin{tabular}{|c|c|c|c|c|c|c|}
\hline $\begin{array}{l}\text { Unidade da } \\
\text { Federação }\end{array}$ & $\begin{array}{c}\text { Universidades } \\
\text { Federais }\end{array}$ & Total de Vagas & $\begin{array}{l}\text { Vagas para ampla } \\
\text { concorrência }\end{array}$ & \multicolumn{2}{|c|}{$\begin{array}{l}\text { Vagas para negras/os } \\
\text { (números absolutos e } \\
\text { percentuais) }\end{array}$} & $\begin{array}{l}\text { Vagas para } \\
\text { Pessoas com } \\
\text { Deficiência }\end{array}$ \\
\hline \multicolumn{7}{|c|}{ Região Norte } \\
\hline$A C$ & Ufac & 68 & 66 & 2 & $2,94 \%$ & 0 \\
\hline AP & Unifap & 174 & 167 & 7 & $4,02 \%$ & 0 \\
\hline AM & Ufam & 444 & 425 & 16 & $3,60 \%$ & 3 \\
\hline \multirow{4}{*}{ PA } & Ufopa & 130 & 97 & 24 & $18,46 \%$ & 8 \\
\hline & Ufpa & 532 & 527 & 5 & $0,93 \%$ & 0 \\
\hline & Ufra & 94 & 94 & 0 & $0,00 \%$ & 0 \\
\hline & Ufesspa & 329 & 329 & 0 & $0,00 \%$ & 0 \\
\hline RO & Unir & 150 & 138 & 9 & $6,00 \%$ & 3 \\
\hline RR & UFRR & 154 & 151 & 3 & $1,94 \%$ & 0 \\
\hline TO & UFT & 203 & 201 & 2 & $0,98 \%$ & 0 \\
\hline Total Norte & & 2.278 & 2.195 & 69 & $3,02 \%$ & 14 \\
\hline \multicolumn{7}{|c|}{ Região Nordeste } \\
\hline AL & Ufal & 373 & 367 & 4 & $1,07 \%$ & 2 \\
\hline \multirow{4}{*}{ BA } & Ufba & 468 & 456 & 12 & $2,56 \%$ & 0 \\
\hline & Ufob & 278 & 270 & 8 & $2,87 \%$ & 0 \\
\hline & UFRB & 363 & 346 & 12 & $3,30 \%$ & 5 \\
\hline & UFSB & 106 & 92 & 14 & $13,2 \%$ & 0 \\
\hline \multirow{3}{*}{ CE } & UFC & 197 & 197 & 0 & $0,00 \%$ & 0 \\
\hline & Ufca & 117 & 114 & 2 & $1,70 \%$ & 1 \\
\hline & Unilab & 155 & 150 & 5 & $3,22 \%$ & 0 \\
\hline MA & Ufma & 250 & 250 & 0 & $0,00 \%$ & 0 \\
\hline \multirow{2}{*}{ PB } & UFCG & 174 & 174 & 0 & $0,00 \%$ & 0 \\
\hline & UFPB & 253 & 253 & 0 & $0,00 \%$ & 0 \\
\hline \multirow{3}{*}{$P E$} & UFPE & 175 & 172 & 3 & $1,71 \%$ & 0 \\
\hline & UFRPE & 206 & 199 & 7 & $3,39 \%$ & 0 \\
\hline & Univasf & 283 & 279 & 4 & $1,41 \%$ & 0 \\
\hline $\mathrm{Pl}$ & Ufpi & 321 & 283 & 5 & $1,55 \%$ & 33 \\
\hline \multirow{2}{*}{ RN } & Ufersa & 171 & 162 & 8 & $4,67 \%$ & 1 \\
\hline & UFRN & 547 & 532 & 12 & $2,19 \%$ & 3 \\
\hline SE & UFS & 174 & 172 & 2 & $1,14 \%$ & 0 \\
\hline Total Nordeste & & 4.611 & 4.468 & 98 & $2,12 \%$ & 45 \\
\hline
\end{tabular}


2. No levantamento realizado, não estão computadas as vagas de concursos para o cargo de professor-titularLivre da carreira de magistério superior (por geralmente oferecerem apenas uma vaga por edital, dada a natureza do cargo), de concursos para a Carreira de Magistério do Ensino Básico, Técnico e Tecnológico (EBTT), que, em geral, correspondem às/ aos docentes dos Colégios de Aplicação que integram as universidades federais) e de processos seletivos para professoras/ es substitutas/os, que não integram o quadro efetivo das universidades federais.

\begin{tabular}{|c|c|c|c|c|c|c|}
\hline $\begin{array}{l}\text { Unidade da } \\
\text { Federação }\end{array}$ & $\begin{array}{c}\text { Universidades } \\
\text { Federais }\end{array}$ & Total de Vagas & $\begin{array}{l}\text { Vagas para ampla } \\
\text { concorrência }\end{array}$ & \multicolumn{2}{|c|}{$\begin{array}{l}\text { Vagas para negras/os } \\
\text { (números absolutos e } \\
\text { percentuais) }\end{array}$} & $\begin{array}{l}\text { Vagas para } \\
\text { Pessoas com } \\
\text { Deficiência }\end{array}$ \\
\hline \multicolumn{7}{|c|}{ Região Centro-Oeste } \\
\hline DF & UnB & 263 & 260 & 3 & $1,14 \%$ & 0 \\
\hline GO & UFG & 392 & 309 & 1 & $0,25 \%$ & 82 \\
\hline MS & UFMS & 366 & 315 & 39 & $10,65 \%$ & 12 \\
\hline \multirow{2}{*}{ MT } & UFGD & 195 & 145 & 40 & $20,51 \%$ & 10 \\
\hline & UFMT & 438 & 325 & 87 & $19,86 \%$ & 26 \\
\hline \multicolumn{2}{|c|}{ Total Centro-Oeste } & 1.654 & 1.354 & 170 & $10,27 \%$ & 130 \\
\hline \multicolumn{7}{|c|}{ Região Sudeste } \\
\hline ES & UFES & 272 & 270 & 2 & $0,73 \%$ & 0 \\
\hline \multirow{11}{*}{ MG } & UFJF & 283 & 280 & 3 & $1,06 \%$ & 0 \\
\hline & UFJS & 132 & 129 & 2 & $1,51 \%$ & 1 \\
\hline & Ufla & 167 & 124 & 34 & $20,35 \%$ & 9 \\
\hline & UFMG & 572 & 553 & 18 & $3,14 \%$ & 1 \\
\hline & Ufop & 104 & 80 & 16 & $15,38 \%$ & 8 \\
\hline & UFU & 52 & 52 & 0 & $0,00 \%$ & 0 \\
\hline & UFV & 15 & 15 & 0 & $0,00 \%$ & 0 \\
\hline & UFTM & 120 & 120 & 0 & $0,00 \%$ & 0 \\
\hline & UFVJM & 245 & 217 & 23 & $9,38 \%$ & 5 \\
\hline & Unifal & 78 & 78 & 0 & $0,00 \%$ & 0 \\
\hline & Unifei & 18 & 15 & 3 & $16,66 \%$ & 0 \\
\hline \multirow{4}{*}{ RJ } & UFF & 499 & 493 & 5 & $1,00 \%$ & 1 \\
\hline & UFRJ & 573 & 558 & 14 & $2,44 \%$ & 1 \\
\hline & UFRRJ & 162 & 162 & 0 & $0,00 \%$ & 0 \\
\hline & Unirio & 57 & 57 & 0 & $0,00 \%$ & 0 \\
\hline \multirow{3}{*}{ SP } & UFABC & 169 & 159 & 8 & $4,73 \%$ & 2 \\
\hline & UFSCar & 244 & 244 & 0 & $0,00 \%$ & 0 \\
\hline & Unifesp & 255 & 251 & 3 & $1,17 \%$ & 1 \\
\hline \multicolumn{2}{|c|}{ Total Sudeste } & 4.017 & 3.857 & 131 & $3,26 \%$ & 29 \\
\hline
\end{tabular}

......

velmente inferiores aos dos totais de vagas para docentes nessas instituições no período em questão. Seguramente, o número total de vagas oferecidas, no período examinado, deve ter sido superior ao que encontramos, mas isso não impede que os resultados identificados no levantamento realizado, dado seu expressivo alcance, mostrem uma clara tendência de como a Lei n.o 12.990/2014 está sendo aplicada no âmbito específico dos concursos da carreira de magistério superior das universidades federais ${ }^{2}$. 


\begin{tabular}{|c|c|c|c|c|c|c|}
\hline $\begin{array}{l}\text { Unidade da } \\
\text { Federação }\end{array}$ & $\begin{array}{c}\text { Universidades } \\
\text { Federais }\end{array}$ & Total de Vagas & $\begin{array}{l}\text { Vagas para ampla } \\
\text { concorrência }\end{array}$ & \multicolumn{2}{|c|}{$\begin{array}{l}\text { Vagas para negras/os } \\
\text { (números absolutos e } \\
\text { percentuais) }\end{array}$} & $\begin{array}{l}\text { Vagas para } \\
\text { Pessoas com } \\
\text { Deficiência }\end{array}$ \\
\hline \multicolumn{7}{|c|}{ Região Sul } \\
\hline \multirow{2}{*}{$P R$} & UFPR & 312 & 312 & 0 & $0,00 \%$ & 0 \\
\hline & UTFPR & 208 & 166 & 30 & $14,42 \%$ & 12 \\
\hline \multirow{8}{*}{ RS } & Furg & 138 & 138 & 0 & $0,00 \%$ & 0 \\
\hline & UFCSPA & 62 & 62 & 0 & $0,00 \%$ & 0 \\
\hline & UFFS & 142 & 140 & 2 & $0,00 \%$ & 0 \\
\hline & UFPel & 175 & 130 & 33 & 18,85 & 12 \\
\hline & UFRGS & 332 & 325 & 7 & $2,10 \%$ & 0 \\
\hline & UFSM & 287 & 199 & 58 & $20,20 \%$ & 30 \\
\hline & Unila & 145 & 130 & 10 & $6,89 \%$ & 5 \\
\hline & Unipampa & 214 & 158 & 39 & $18,22 \%$ & 17 \\
\hline SC & UFSC & 480 & 291 & 95 & $19,79 \%$ & 94 \\
\hline \multicolumn{2}{|c|}{ Total Sul } & 2.495 & 2.051 & 274 & $10,98 \%$ & 170 \\
\hline \multicolumn{2}{|c|}{ Total Nacional } & 15.055 & 13.925 & \multicolumn{2}{|c|}{742} & 388 \\
\hline \multicolumn{2}{|c|}{ \% Total Nacional } & $100 \%$ & $92,5 \%$ & \multicolumn{2}{|c|}{$4,93 \%$} & $2,57 \%$ \\
\hline
\end{tabular}

Fonte: os autores (2018).

Com base nos dados sistematizados na Tabela 3, a constatação mais relevante a destacar é que os concursos para a carreira de magistério superior das universidades federais estão longe de atingir os objetivos da ação afirmativa materializada na Lei n.o 12.990/2014, haja vista que das 15.055 vagas identificadas, apenas 742 foram reservadas para negras/os (aproximadamente 4,93\%) e 388 para pessoas com deficiência (aproximadamente 2,57\%). Essa distribuição é heterogênea entre as diferentes instituições, já que algumas efetivamente contemplaram, em seus editais, aproximadamente o percentual de $20 \%$ de vagas reservadas para negras/ os (nove instituições: Ufopa, UFGD, UFMT, Ufla, Unifei, UFPel, Unipampa, UFSM e UFSC), enquanto outras não reservaram literalmente nenhuma vaga para candidatas/os negras/os (16 instituições: Ufra, Ufesspa, UFC, Ufma, UFCG, UFPB, UFU, UFV, UFTM, Unifal, UFRRJ, Unirio, UFSCar, UFPR, Furg, UFCSPA), com situações variadas entre os dois extremos.

O que se observa, portanto, é um quadro que confirma os temores apontados na

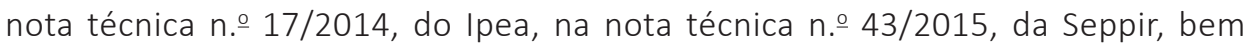
como no voto do ministro Luís Roberto Barroso, do STF, Relator da ADC n.o 41, antes mencionados, quando se referem explícita e especificamente às eventuais dificuldades de garantia da reserva, para candidatas/os negras/os, de $20 \%$ das vagas de concursos públicos para professoras/es de universidades federais. Como mostramos anteriormente, porém, nove universidades, algumas a partir dos pareceres 
de suas respectivas Procuradorias Federais - como a UFGD e a Ufopa -, encontraram mecanismos para assegurar o cumprimento da lei - seja por meio do sorteio das vagas que serão reservadas para candidatas/os negras/os, seja por meio da reserva de vagas nas áreas em que haja candidatas/os negras/os aprovadas/os no concurso -, partindo do princípio de que a reserva de $20 \%$ das vagas deve ter como parâmetro o total das vagas oferecidas em um mesmo edital, ainda que diferentes áreas de conhecimento ofereçam um número de vagas inferior a três.

O que constatamos, porém, é que a não reserva de $20 \%$ das vagas na grande maioria dos concursos é decorrência de práticas administrativas que restringem o alcance da lei, a exemplo de editais que de fato oferecem menos de três vagas por concurso para docente, ainda que muitas vezes, em um mesmo dia e/ou uma mesma semana, sejam publicados no Diário Oficial da União (DOU) diversos editais de uma mesma universidade, cada um com uma única vaga, como se observa em concursos da UFCG, UnB, Ufes, UFJS, UFMG, UFU, UFV, UFG, Unifal, Ufabc, UFSCar, Unifesp, Furg e Unila, dentre outras instituições.

Por outro lado, também constatamos que a grande maioria dos editais de concurso para a carreira de magistério superior de universidades federais, quando oferecem mais de três vagas - às vezes, dezenas de vagas -, trazem dispositivos que explicitamente restringem a reserva de $20 \%$ para candidatas/os negras/os a situações em que haja uma oferta de três ou mais vagas por "área", "área de conhecimento", "área específica de conhecimento", "disciplina/área de conhecimento", "setor de estudo", "tema do concurso", "unidade acadêmica", "cargo-função", "cargo/área", "cargo/especialidade", "opção de vaga", "especialidade", "departamento de ensino" ou "campus". Tal opção implica uma interpretação restritiva da Lei n.o 12.990/2014, o que inviabiliza a consecução dos objetivos da ação afirmativa prevista para candidatas/os negras/os, outra vez contrariando diretrizes propostas pelo Ipea, Seppir e STF, como visto anteriormente.

\section{Para continuar a pensar}

Entendemos urgente um amplo debate acerca da uniformização de procedimentos relativos aos concursos públicos para docentes das universidades federais, de maneira a efetivamente alcançar o percentual de 20\% de reserva de vagas para candidatas/os negras/os legalmente estabelecida, respeitada a autonomia universitária constitucionalmente prevista. Seguramente, a Associação Nacional dos Dirigentes das Instituições Federais de Ensino Superior no Brasil (Andifes) e a Associação Nacional de Pesquisadores Negros (ABPN) poderiam ter um importante papel com vistas ao encaminhamento desses debates e de seus desdobramentos. 
Também parece fundamental a promoção de estratégias de recrutamento que estimulem candidatas/os negras/os a realizarem concursos públicos para docentes das universidades federais, de maneira a ocuparem, no mínimo, as vagas reservadas no percentual de $20 \%$. No âmbito restrito dos objetivos de nossa investigação, não temos ideia se, de fato, as vagas reservadas para negras/os, ainda que em um patamar muito inferior ao legalmente previsto, estão sendo de fato preenchidas por candidatas/os negras/os. Um outro trabalho de pesquisa precisa ser feito no sentido de verificar se candidatas/os negras/os estão se inscrevendo nos concursos que oferecem reserva de vagas - e nos demais também -, se estão sendo aprovadas/os e passando a trabalhar como professoras/es de magistério superior nas universidades federais. Também seria importante identificar outras características dessas/es candidatas/os, a exemplo de sexo, idade, área de formação, titulação, área de atuação, trajetória profissional. De momento, porém, nossa hipótese é que parte das vagas reservadas não está sendo preenchida por candidatas/os negras/os, por razões diversas, o que implica um alcance ainda mais restrito da política de ação afirmativa proposta por meio da Lei n.o 12.990/2014.

Também se faz importante refletir acerca da relevância da implantação de cotas para negras/os nos cursos de pós-graduação stricto sensu (mestrado e doutorado), de maneira a ampliar o número potencial de candidatas/os habilitadas/os a pleitear vaga na carreira docente em universidades federais. Como mostram Anna Carolina Venturini e João Feres Júnior (2018), em estudo recente, várias instituições passaram a adotar cotas raciais para o conjunto de seus cursos de mestrado e doutorado, como UFG, Ufba, Ufam, UFMG, UFGD, UFU, UFT, UFPel, Ufpi e UFFS.

Parece claro que a própria Lei n. 12.990/2014, ao ser a primeira legislação federal a prever cotas para grupos específicos de raça/cor, independentemente de outros marcadores sociais associados à renda, evidencia o alcance ainda limitado das cotas sociais e raciais de ingresso em cursos de graduação, dada a expressiva exclusão de pretas/os e pardas/os dos quadros do serviço público federal, como mostrado anteriormente. Nesse sentido, a Lei n. 12.990/2014 pode ser interpretada como iniciativa que legitima a aprovação de cotas raciais também em cursos de pós-graduação stricto sensu, haja vista a forte prevalência de pessoas autodeclaradas brancas nos cursos de mestrado e doutorado - valores estimados na ordem de 70\%, a partir de estudo realizado pelos professores Marcio de Castro Silva Filho e Sérgio da Costa Côrtes (2016), integrantes do Grupo de Trabalho Inclusão de Estudantes de Pós-Graduação, da Coordenação de Aperfeiçoamento de Pessoal de Nível Superior (Capes), utilizando dados da Plataforma Sucupira (2013/2015), do Censo da Educação Superior (2011/2013) e da Relação Anual de Informações Sociais (Rais, 2013/2014). 
Dois outros desdobramentos recentes decorrentes justamente da aprovação da Lei n. 12.990/2014 também saltam da esfera estrita dos concursos públicos no âmbito do serviço público federal e repercutem diretamente sobre o acesso e a permanência de estudantes de graduação. Um primeiro foi o anúncio de que o Instituto Tecnológico de Aeronáutica (ITA), o Instituto Militar de Engenharia (IME), o Colégio Naval e a Academia da Força Aérea, a partir de 2019, reservarão 20\% de suas vagas para candidatas/os negras/os (Folha On-Line, 2018), a partir do entendimento, consolidado pelo STF em abril de 2018, de que

as Forças Armadas integram a Administração Pública Federal, de modo que a vagas oferecidas nos concursos por elas promovidos sujeitam-se à política de cotas prevista na Lei n.․⒓990/2014 (Brasil, 2018).

Um segundo desdobramento importante é o Decreto n. 9 9.427, de 28 de junho de 2018, que "reserva aos negros trinta por cento das vagas oferecidas nas seleções para estágio no âmbito da administração pública federal direta, autárquica e fundacional". O detalhe não muito promissor deste decreto é que a reserva de vagas para negras/os também fica condicionada a um número mínimo de três vagas no processo de seleção de estagiárias/os.

Resta ainda dizer que no atual cenário das universidades federais, estudantes negras/os, seja em nível de graduação, seja em nível de pós-graduação, muitas vezes não encontram referências positivas de identificação profissional no corpo docente de seus cursos e universidades, considerando que a majoritária branquidão é um marco identitário altamente impactante. Parece fundamental, então, a realização de múltiplos esforços no sentido da criação de um ambiente de ensino/aprendizagem em que a diversidade de raça/cor de toda a comunidade acadêmica seja valorizada. Por outro lado, igualmente importante é que se valorize a multiplicidade de saberes produzidos em nossa sociedade, de maneira que o conhecimento científico produzido nos moldes eurocêntricos possa dialogar com outras linhagens e perspectivas de interpretação e de transformação do mundo. Somente assim as nossas universidades estarão à altura de contribuir efetivamente para a construção de uma sociedade onde ciência, arte, tecnologia e cultura sejam patrimônio de todas/os, e não privilégio de uma pequena elite. 


\section{Referências}

BRASIL. Decreto n. 9.427, de 28 de junho de 2018. "Reserva aos negros trinta por cento das vagas oferecidas nas seleções para estágio no âmbito da administração pública federal direta, autárquica e fundacional". Brasília, 2018a. Disponível em: <http://www.imprensanacional.gov.br/web/guest/materia/-/asset_publisher/Kujrw0TZC2Mb/content/id/27934784/do1-2018-06-29-decreto-n-9-427-de-28-de-junho-de-2018-27934697>. Acesso em: 23 Jul. 2018.

. Embargos de Declaração na Ação Declaratória de Constitucionalidade no 41. Brasília: Supremo Tribunal Federal, 2018b. Disponível em: <http://redir.stf.jus.br/paginadorpub/paginador.jsp?docTP=TP\&docID=14763674>. Acesso em: 29.07.2018.

—. Portaria Normativa n. 9 4, de 06 de abril de 2018. "Regulamenta o procedimento de heteroidentificação complementar à autodeclaração dos candidatos negros, para fins de preenchimento das vagas reservadas nos concursos públicos federais, nos termos da Lei n¹2.990, de 9 de junho de 2014”. Brasília: Ministério do Planejamento, Orçamento e Gestão (MPOG). Secretaria de Gestão de Pessoas, 2018c. Disponível em: <http://www.dpu.def.br/images/stories/Infoleg/2018/04/10/ portaria_mpog2.pdf>. Acesso em: 08 Abr. 2018.

—. Ação Declaratória de Constitucionalidade 41 (Inteiro Teor do Acórdão), DF, 2017. "Tem como objeto a Lei $n^{\circ} 12.990 / 2014$, que reserva aos negros $20 \%$ (vinte por cento) das vagas oferecidas nos concursos públicos para provimento de cargos efetivos e empregos públicos no âmbito da administração pública federal direta e indireta". Brasília: STF, 2017. Disponível em: <file://Users/gilsonggr72/Downloads/ texto_312447860\%20(1).pdf>. Acesso em: 02 Out. 2017.

—. Parecer no 135/2016/PF-UFOPA/PGF/AGU, relativo a edital de concurso público para provimento de cargos de docentes do magistério superior. Advocacia-Geral da União. Procuradoria-Geral Federal. Santarém: Procuradoria Federal junto à Universidade Federal do Oeste do Pará (Ufopa), 2016.

— . Nota Técnica n. 43/2015 - SPAA/SEPPIR/PR. Brasília: SEPPIR, 2015a. Disponível em: <file:///Users/gilsonggr72/Downloads/NOTA+TECNICA+43\%20(1).pdf>. Acesso em: 05 Out. 2017.

—. Servidores Públicos Federais: perfil 2015 (folder). Brasília: Enap, 2015b. Disponível em: http://antigo.enap.gov.br/images//150610_folder_estudos_enap_servidores_publicos_federais_perfil_2015.pdf. Acesso em 02.10.2017. 
Lei no 12.990, de 9 de junho de 2014. "Dispõe sobre a reserva aos negros $20 \%$ (vinte por cento) das vagas oferecidas nos concursos públicos para provimento de cargos efetivos e empregos públicos no âmbito da administração pública federal, das autarquias, das fundações públicas, das empresas públicas e das sociedades de economia mista controladas pela União". Brasília, 2014a. Disponível em: <http:// www.planalto.gov.br/ccivil_03/_ato2011-2014/2014/lei/l12990.htm>. Acesso em 07 Out. 2017.

Parecer no 074/2014/PF-UFGD/PGF/AGU. “Edital de concurso público para provimento de cargos de docentes do magistério superior. Advocacia-Geral da União. Procuradoria-Geral Federal. Dourados: Procuradoria Federal junto à Universidade Federal da Grande Dourados (UFGD), 2014b.

—_. "Servidores Públicos Federais: raça/cor 2014" (foder). Brasília: Enap, 2014c. Disponível em: <http://antigo.enap.gov.br/images//150317_servidores_publicos_ federais_raca_cor.pdf>. Acesso em: 02 Out. 2017.

—. Arguição de Descumprimento de Preceito Fundamental n 186 (Inteiro Teor do Acórdão). Tem como objeto os atos que instituíram sistema de reserva de vagas com base em critério étnico-racial (cotas) no processo de seleção para ingresso na Universidade de Brasília. Brasília: STF, 2012a. Disponível em: <http://redir.stf.jus. $\mathrm{br} /$ paginadorpub/paginador.jsp?docTP=TP\&doclD=6984693>. Acesso em: 02 Out. 2017.

Lei $n$ ㅇ 12.711, de 29 de agosto de 2012. “Dispõe sobre o ingresso nas universidades federais e nas instituições federais de ensino técnico de nível médio e dá outras providências". Brasília, 2012b. Disponível em: <http://www.planalto.gov.br/ ccivil_03/_ato2011-2014/2012/lei/l12711.htm>. Acesso em: 07 Out. 2017.

—. Lei no 12.288, de 20 de julho de 2010. "Institui o Estatuto da Igualdade Racial; altera as Leis n.. 7.716 , de 5 de janeiro de 1989, 9.029, de 13 de abril de 1995, 7.347, de 24 de julho de 1985, e 10.778, de 24 de novembro de 2003". Disponível em: <http://www.planalto.gov.br/ccivil_03/_Ato2007-2010/2010/Lei/L12288. htm>. Acesso em: 05 Set. 2017.

— Projeto de Lei no 1.332, de 1983, de autoria do deputado Abdias Nascimento. "Dispõe sobre ação compensatória, visando a implementação do princípio da isonomia social do negro, em relação aos demais segmentos étnicos da população brasileira, conforme direito assegurado pelo artigo 153, parágrafo primeiro, da Constituição da República". Disponível em: <http://www.camara.gov.br/proposicoesWeb/fichadetramitacao?idProposicao=190742>. Acesso em: 07 Out. 2017. 
CARVALHO, José Jorge de. Inclusão étnica e racial no ensino superior: um desafio para as universidades brasileiras. Série Antropologia, n. 382, Brasília: Departamento de Antropologia da Universidade de Brasília, 2005. Disponível em: <http://www. dan.unb.br/images/doc/Serie382empdf.pdf>. Acesso em: 22 Set. 2017.

CARVALHO, José Jorge de; SEGATO, Rita Laura. Uma proposta de cotas para estudantes negros na Universidade de Brasília. Série Antropologia, n. 314. Brasília: Departamento de Antropologia da Universidade de Brasília, 2002. Disponível em: <http:// www.dan.unb.br/images/doc/Serie314empdf.pdf>. Acesso em: 22 Set. 2017.

CONSELHO FEDERAL DA ORDEM DOS ADVOGADOS DO BRASIL (CFOAB). "Petição Inicial da Ação Declaratória de Constitucionalidade (com pedido de medida cautelar), tendo por objeto a Lei no 12.990, de 09 de junho de 2014". Disponível em: <http://s. conjur.com.br/dl/adc-41-oab-declaracao.pdf>. Acesso em: 02 Out. 2017.

DEMOCRATAS. "Petição inicial da Arguição de Descumprimento de Preceito Fundamental no 186 (com pedido de suspensão liminar), visando à declaração de atos do Poder Público que resultaram na instituição de cotas raciais na Universidade de Brasília", 2009. Disponível em: <http://www.stf.jus.br/portal/geral/verPdfPaginado. asp id=400108\&tipo=TP\&descricao=ADPF\%2F186> . Acesso em: 02 Out. 2017.

FERREIRA, Gianmarco Loures. Sub-Representação legal nas ações afirmativas: a Lei de Cotas nos concursos públicos. Dissertação (Mestrado em Direito, Estado e Constituição), Faculdade de Direito da Universidade de Brasília, Brasília, 2016.

FOLHA ON-LINE. "Para cumprir a lei, ITA adota cotas raciais no vestibular". Disponível em: <https://www1.folha.uol.com.br/educacao/2018/07/para-cumprir-a-lei-ita-adota-cotas-raciais-no-vestibular.shtml>. Acesso em: 31 Jul. 2018.

GOMES, Nilma Lino; MARTINS, Aracy Alves (Orgs.). Afirmando direitos: acesso e permanência de jovens negros na universidade. Belo Horizonte: Autêntica, 2004.

GUIMARÃES, Antônio Sérgio Alfredo. As cotas nas universidades públicas 20 anos depois. In: ARTES, Amélia; UNBEHAUM, Sandra; SILVÉRIO, Valter (Orgs.). Ações afirmativas no Brasil - reflexões e desafios para a pós-graduação, p. 93-124. São Paulo: Cortez; Fundação Carlos Chagas, 2016.

SILVA, Josenilton; PINHEIRO, Luana; JACCOUD, Luciana; SILVA, Waldemir. A construção de uma política de promoção da igualdade racial: uma análise dos últimos 20 anos, p. 147-170. Brasília: Ipea, 2009a. 
SILVA, Tatiana Dias. Cor e raça nos quadros da administração pública. Trabalho apresentado no XIX Encontro Nacional de Estudos Populacionais, Abep, realizado em São Pedro (SP), de 24 a 28 de novembro de 2014. Disponível em: <http://www. abep.org.br/publicacoes/index.php/anais/article/viewFile/2262/2217>. Acesso em: 12 Out. 2017.

SILVA, Tatiana Dias; SILVA, Josenilton Marques da. Nota Técnica n. 17, sobre a "reserva de vagas para negros em concursos públicos: uma análise a partir do Projeto de Lei 6.738/2013". Brasília: Ipea, 2014. Disponível em: <http://repositorio.ipea. gov.br/bitstream/11058/5781/1/NT_n17_Reserva-vagas-negros-concursos-publicos_Disoc_2014-fev.pdf>. Acesso em: 30 Ago. 2017.

SILVA, Tatiana Dias; VOLPE Ana Paula Sampaio. Ações afirmativas para ingresso na administração pública. Trabalho apresentado no ST 25 - Relações raciais: desigualdades, identidades e políticas públicas, do 370 Encontro Anual da Anpocs, Águas de Lindóia (SP), 23 a 27 de outubro de 2013. Disponível em: <http://www.anpocs.com/ index.php/papers-37-encontro/st/st25/8563-acoes-afirmativas-para-ingresso-de-negros-na-administracao-publica/file>. Acesso em: 12 Out. 2017.

SILVA FILHO, Marcio de Castro; CÔRTES, Sérgio da Costa. Estudo preliminar socioeconômico aplicando os dados do Censo da Educação Superior e da RAIS nos alunos da Pós-graduação. Brasília: Apresentação em powerpoint, 2016.

SOUZA, Marcilene Garcia de. Ações afirmativas e inclusão de negros por "cotas raciais" nos serviços públicos do Paraná. Tese (Doutorado em Sociologia) - Universidade Estadual Paulista Júlio de Mesquita Filho, Campus Araraquara, 2010.

VENTURINI, Anna Carolina; FERES JÚNIOR, João. Ações afirmativas em cursos de pós-graduação acadêmicos de universidades públicas. Boletim Gemaa, n. 6, p. 1-9, 2018. Disponível em: <http://gemaa.iesp.uerj.br/wp-content/uploads/2018/07/Boletim-6.pdf>. Acesso em: 23 Jul. 2018.

VOLPE, Ana Paula Sampaio; SILVA, Tatiana Dias. Reserva de vagas para negros na administração pública. Relatório de pesquisa. Brasília: Ipea, 2016. Disponível em: <http://ipea.gov.br/agencia/images/stories/PDFs/relatoriopesquisa/160413_relatorio_reserva_vagas_negros_adm_publica.pdf>. Acesso em: 10 Nov. 2017. 